\title{
Multi-agency pilot intervention for high intensity service users of emergency public services: the Isle of Wight Integrated Recovery Programme
}

\section{Abstract}

\section{Purpose}

This paper describes the design, implementation and evaluation of a small UK case study of a mentoring style pilot intervention integrating a specially trained police officer alongside mental health professionals to support highly intensive service users of emergency services.

\section{Design/methodology/approach}

The development of the conceptual framework informing the mentoring intervention is described and its implementation evaluated using a range of qualitative and quantitative outcome measures.

\section{Findings}

The four high intensity service users involved in the pilot had internalised the need to participate in recommended recovery pathways. Mental health nurses reported improved compliance with treatment. Although the sample was small, the number of police mental health crisis detentions was reduced by $66 \%$ after one year and by $100 \%$ after 18 months. Usage of other emergency public services had also drastically reduced, or been eliminated altogether.

\section{Research limitations/implications}

Limited time and resources and the need for a solution that could be implemented as soon as possible meant a pragmatic design, implementation and evaluation.

\section{Practical implications}

The study indicated that a wider roll-out of the new multi-agency mentoring model would be beneficial.

\section{Originality/value}

This is the first intervention to integrate mental health a trained police officer directly into the care pathway of repeated users of emergency public services with complex mental health needs.

Keywords: Street Triage, High Intensity Users of Emergency Public Services, integrated care, multiagency mentoring 
Purpose

This paper describes the design, implementation and evaluation of a small UK case study of a mentoring-style pilot intervention, a new model of care integrating a specially trained police officer alongside mental health professionals to support highly intensive service users of emergency services by way of mentoring-style intervention called the Integrated Recovery Programme [IRP]. Limited time and resources and the need for a solution that could be implemented as soon as possible meant a pragmatic design, implementation and evaluation. The case examples are therefore used for demonstrative purpose before discussing the implications for practice, policy and research.

\section{Background}

\section{The need to reduce police mental health crisis detentions}

In the context of rising demand for emergency public services (Keogh Report, 2015) and mental health services (DoH, 2015), matched by a backdrop of financial constraints on both the NHS and the police (O'Hara, 2014) and rising number of mental health patients in the prison population (DoH 2001; Adebowale, 2013), concerns have been expressed over the increasing number of police mental health detentions, especially detentions in police custody (RCPsych 2011; McNicoll, 2012; HMIC, HMIP, CQC and HIW, 2013).

A mental health police detention is a power that police have under Section 136 of the Mental Health Act 1983 (amended 2007) to ensure that, in their best interest or for the protection of others, those thought to have mental health problems in a public place are taken to a 'place of safety' (psychiatric emergency ward, specialist suite or police custody) where they can be held for up to $72 \mathrm{hrs}$ until it is ascertained whether the detention remains appropriate. ${ }^{1}$ Across England and Wales in 2012/13, a total of 21,814 individuals were detained by the police before being given a mental health assessment by a relevant professional with 14,053 assessed in a hospital setting (64\%) and 7,761 in a police cell (36\%). Of those 21,814 individuals, $82 \%$ did not progress to any further Section of the Mental Health Act after their clinical assessment (HSCIC, 2013) causing unnecessary financial burden on National Health Service [NHS].

To remedy the problem, key policy reports have recommended that health and criminal justice agencies work in closer partnership (Docking et al 2008; Bradley, 2009; HM Government; 2014; MHNNHSC and ACPOs, 2015). Multi-agency partnership delivery groups were established across England (police, mental health services, local authority, Emergency Department [ED] and ambulance) to focus on early intervention for the purpose of reducing the number of people being subjected to mental health legislation (Parliament UK, 2015).

\section{Street Triage (ST) initiatives}

In the USA, crisis intervention teams [CITs] were introduced to better respond to mental health related police calls (Compton et al 2008; Reuland et al, 2010). These innovative schemes involve police officers with formal mental health and crisis intervention training, or co-responder police and mental health professionals, or a mix of both adapted to the local

\footnotetext{
${ }^{1}$ http://www.legislation.gov.uk/ukpga/1983/20/section/136
} 
context (Helfgott et al, 2016). These schemes inspired the introduction of locally funded Street Triage [ST] interventions in England, first in Cleveland in the North East in August 2012 (three mental health nurses and a support worker in the police control room advising police and responding to callers) and then in Hampshire/Isle of Wight in November 2012 (a mental health nurse and a police officer going on patrol together to attend mental health related incidents) (MHNNHSC and ACPOs, 2015).

In Cleveland (Dyer et al, 2015) and Hampshire Isle of Wight (MHN NHSC and ACPOs, 2015) there were soon significantly fewer S136 detentions. Because of promising early findings, the Department of Health and the Home Office funded nine ST pilot schemes. However, there were concerns that some of these nationally-funded pilot sites (i.e. Devon \& Cornwall and Sussex) still detained high numbers of people under S136 in police custody (Parliament UK, 2015). The high number of detentions in police custody (despite overall reductions) was explained as the consequence of ST only being offered on a part time basis. (Wilson-Palmer and Poole, 2015; Heslin et al, 2016). A nationally-funded pilot in North Yorkshire showed an increase of 19.4\% in S136 detentions in the first year (See Reveruzzi and Pilling, 2016), but later a decrease of 50\% (Irvine et al, 2016). The final evaluation report of the nationally funded pilot sites showed a large variation in the results with an average reduction of $11.8 \%$ for S136 detentions (Reveruzzi and Pilling, 2016) with 18.3\% for Sussex, later 39\% (Heslin et al, 2016) against a reduction of $56 \%$ in the first year for the locally funded ST in Northumberland, Tyne and Wear (Keown et al, 2016).

\section{Repeated service users of public emergency services in high intensity moments of crisis or} High Intensity Users [HIUs]

The introduction of ST in Hampshire Isle of Wight in November 2012 (called Operation Serenity) ${ }^{2}$ led to $25 \%$ reduction in the use of S136 detentions within 6 months and $70 \%$ within four years, the elimination of police custody as a place of safety and a rise in the appropriateness of S136 detentions from 20\% to around 75\% (MHN NHSC and ACPOs, 2015, p5). By the end of that first year, the team had identified those service users who were repeatedly requesting the Street Triage team whilst simultaneously using ED, ambulance, GP and other core services, including mental health services.

A total of 69 service users were found to have caused 165 incidents requiring the use of police arrest powers under S136 of the Mental Health Act 1983 (amended 2007). However, it was found that eight highly intensive individuals (11.5\%) had caused 54 crisis incidents (32\%). All eight were female within an age range of 20-63 and with a clinical diagnosis of Emotionally Unstable Personality Disorder [EUPD]/Borderline Personality Disorder [BPD], a secondary diagnosis of anxiety or depression, a documented history of abuse, neglect, domestic violence or abandonment, who were struggling with developing or maintaining close personal relationships.

Termed High Intensity Users [HIUs] by Hampshire Constabulary, all eight were being managed on a regular basis by dedicated mental healthcare co-ordinators who were struggling to achieve any significant therapeutic progress and described these HIUs as 'unmanageable' (i.e. failing to engage, co-operate and attend clinical appointments). Mental

${ }^{2}$ One of the authors, PJ, is the police officer who led Hampshire's Operation Serenity ST Programme on the Isle of Wight, designed the IRP, later re-named Serenity Integrated Mentoring [SIM]. 
health co-ordinators were fearful of discharging them because their often-unacceptable behaviour was negatively impacting on community life, while occasionally bordering on criminal. Their intensive demand profiles presented higher risks of suicide and self-harm while their inappropriate use of emergency services created both direct and indirect risks to the wider community. ${ }^{3}$ Risks also increased within emergency departments, disrupted by their refusal to co-operate with medical staff, reporting false symptoms, pretending to be unconscious or demonstrating aggressive behaviour. ${ }^{4}$

\section{Developing the conceptual framework for the IRP}

Whilst the Street Triage teams had improved the speed and quality of crisis response overall, nothing was in place to address the problem of HIUs. Despite the operational and community risks they posed, only one initiative in England had specifically focussed on HIUs of emergency public services: the Neighbourhood Project in Manchester, a joint NHS and police initiative promoting community based supportive social networks and access to meaningful activity (MHN NHS Confederation and ACPO, 2015). In the USA, some CITs pairing police officers and mental health practitioners added some preventative and followup element for HIUs (Munetz et al, 2006; Andrews and Baldry, 2013; Helfgott et al 2016). However, only two schemes (Houston and Los Angeles) focussed solely on identifying and supporting HIUs (Council of State Governments Justice Center, 2012, 2015). Neither in the USA nor in England did the few initiatives aimed at HIUs include a police officer directly involved in the mental health treatment pathway of HIUs.

As there is a high percentage of mental health patients in the prison population in the UK (DoH 2001; Adebowale, 2013), and an estimated $70 \%$ of male prisoners and $60 \%$ of female prisoners have one or more mental health conditions (OHRN, 2009), and an estimated $12 \%$ of the general population have a Personality Disorder [PD] while between 60 and $80 \%$ of the UK prison population have a PD (Singleton et al, 1998), and some of the HIUs had already interacted with the criminal justice system, the fear was that unless something was done to reduce and eliminate the unpredictable intensive demand behaviour of HIUs they may sooner or later join the prison population.

A model of care was urgently needed that would run in parallel with ST, involve both police and mental health and be based on a mentoring-style approach. The main aim of such a new model of care was that the HIUs show improved personal accountability, social awareness and participation in recommended pathways. This would in turn reduce the risks that HIUs posed to themselves and to the community, including the negative occupational impact on mental health staff who were involved in their care.

The following hypothetical questions were asked:

$\square$ Could the police proactively support the NHS with these increasingly unmanageable and institutionalised patients who were failing to make any real clinical progress?

\footnotetext{
${ }^{3}$ In the Isle of Wight policing area, the local ambulance service operates just five ambulances at any one time, serving 140,000 people (a number which can double in the summer months). Any avoidable requests for an ambulance or unnecessary use of S136 police powers can create huge problems for keeping the community safe.

${ }^{4}$ The characteristics of the HIUs showed a striking resemblance to those identified by Sussex Police during their own ST initiative in Eastbourne: more often than not female, over 30 years of age, a diagnosis of borderline or anti-social personality disorder [BPD], dissociative episodes ('out of body'), co-morbidity, often with a history of sexual abuse or violence, social isolation and downward mobility.
} 
C Could the police be directly involved in the mental health treatment pathways of these patients?

$\square$ Could NHS staff integrate police officers directly within treatment sessions?

To optimise success, a delicate balance of mental health care co-ordinator and police officer was needed and this had to be supported by clinicians, service users, police and NHS managers and their families.

\section{Methodology}

\section{Designing the IRP}

The process of designing the mentoring intervention started with the identification of some core overarching principles. A tag cloud was created based on policy-endorsed recommendations i.e. multi-agency approach, empathy rapport, trust and honesty and space to express emotion but proportionate use of criminal justice (Docking, 2008; Bradley, 2009; Adebawole 2013; HM Government, 2014) and multidisciplinary specialist teams with expertise in the assessment, diagnosis, treatment and management of Borderline Personality Disorder [BPD] for service users who have particularly complex needs and/or high levels of risk (NICE, 2009)

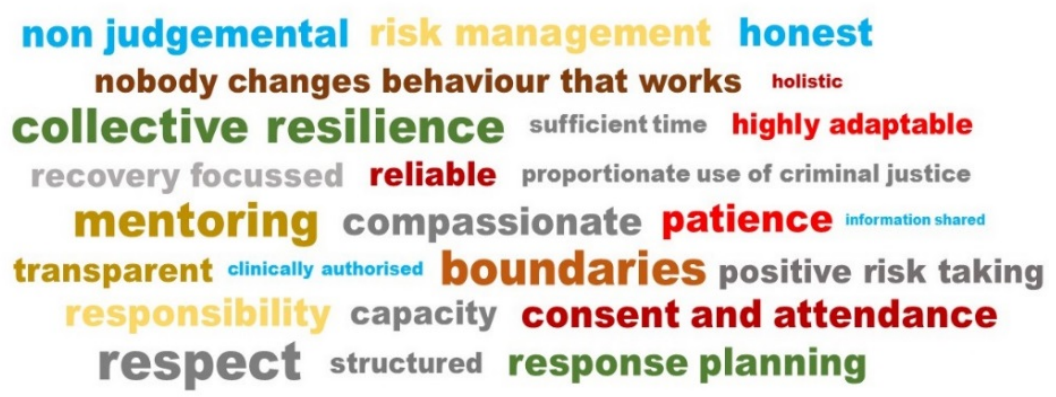

Patients with BDP are the group most often seen by mental health services. They have patterns of behaviour which differ from those expected by society: highly impulsive; experiencing brief mood swings; having a poor sense of self-image and difficulty in sustaining close relationships. (Singleton et al, 1998).

The strategy for change aimed to provide inter-personal support by way of mentoring style discussions based on core supportive messages that were compassionately, but firmly reinforced over the course of several weeks/months. These messages were:

a) We are responsible for the consequences of our actions and we need you to understand what the consequences of your actions will be if they continue.

b) Developing emotional resilience skills in the community is important to your recovery.

c) Detention within a mental health ward does not develop your coping skills. We should all try to avoid it at all costs

d) Positive risk-taking by professionals helps you to take responsibility. A Response Plan will guide responders in making decisions that are in your best interests.

e) We will help you managing your life and developing coping skills 
In order to achieve the aims of the new model of care, the mentoring style intervention would encourage personal accountability, a more consistent and focussed mind set and greater social awareness and competence. A psycho-social approach would best develop skills in relation to the social environment (Durcan, 2014) i.e. emotional intelligence, or the ability to process emotional information and use it to navigate the social environment (Salovey et al, 2004).

Mental health and police (core members) would be supported as appropriate by other professional teams (probation, drug and alcohol teams, housing, and ambulance). For each $\mathrm{HIU}$, the IRP team composition was that which would best fit the underlying causational factors of demand patterns.

\section{Implementing the IRP}

In June 2013, six out of the eight service users (responsible for 42/54 S136 detentions) were offered the opportunity to take part in the new integrated and intensive mentoring model of care. One HIU declined the opportunity and, after three meetings, another was deemed not suitable for the intervention due to her continued refusal to engage. The other two HIUs were not offered the opportunity to take part because one had developed a psychotic disorder and the other would soon be leaving the area.

A priority was profiling the basic behavioural patterns or 'default' behaviour of the HIUs i.e. identify the underlying causational factors of the demand patterns of each HIU in relation to mental health police detentions, use of emergency public services, mental health and other NHS services as this would enable the teams to risk assess and prioritise the most appropriate issues within the mentoring sessions. The (anonymised) profile of the four HIUs that took part in the eighteen-month pilot is described below.

\section{Jane}

Jane was in her mid-40s. She was diagnosed with BPD and had potentially psychopathic traits. She is married with a supportive family living nearby. She made unnecessary requests for ambulance and false claims of accidents. She also made malicious reports of being assaulted by her husband. She regularly abused and threatened mental health and social care staff. She attempted to disrupt the mental health clinical progress of other HIUs and encouraged them to self-harm. She demonstrated manipulation and dishonesty when challenged.

\section{Gena}

Gena was in her early 20s and lived with her boyfriend. She was diagnosed with BPD, autism, ADHD, and an eating disorder (since childhood). She had an alcohol and drug problem. Her immediate family was violent and abusive. Her parents had long been the subject of domestic violence safeguarding, prosecutions and high-risk case conferences. Her wider family was dysfunctional and highly volatile. She behaved in attention-seeking ways in public places. She regularly called mental health services up to 40 times a day. She demonstrated impulsive behaviour and self-harm due to alcohol and drugs. She was frequently anti-social and had sporadically engaged in criminal activities. She claimed to have been raped by a male relative, but had not been believed. 
Susan

Susan was in her mid-40s. She was diagnosed with BPD, mood disorder, sleeping disorder. She had an alcohol problem. She lived alone. Her adult son was in prison and her estranged parents lived nearby. She called NHS, police and ambulance call centres as way of venting emotions (mostly alcohol-related). She was frequently abusive to call takers. She often demonstrated inappropriate and abusive behaviour in her GP practice and in pharmacies. She was unable to control her finances and had a significant gambling problem. She was vulnerable to predatory men whom she often invited into her flat. They also frequently seemed to take financial advantage of her. She called emergency services as of way of coping with their rejection of her.

Tina

Tina was in her early 60s. She was diagnosed with BPD. She lived alone, having lived with her parents all her life until they died. She only became known to mental health/emergency services after their deaths. She regularly called ambulances to her home and threatened to self-harm with a kitchen knife to her wrists, often holding the knife against herself in front of paramedics. She frequently went to a dual carriageway bridge over the river and started climbing railings, threatening to jump off. Drivers were forced to slow down. Once, two drivers stopped and pulled her off the railings. She was employed at large manufacturing company. Outside of work, she had very few social connections and nobody that she could trust.

The pilot started in July 2013 and ran until the end of December 2014. The IRP team met weekly to discuss progress. A police officer did not attend every clinical support session because it was vital that HIUs had private time with their care coordinators. A police officer met the HIUs and their care coordinator between once and four times a month as appropriate to the circumstances. Their life history, diagnosis and the struggles they were having with disordered thoughts and emotions were discussed. The police officer learned what to say and what not to say, how to ask questions without offending or causing upset. The police officer brought to the meetings records of everything that was known to have happened to the HIUs since the previous meeting. The more serious consequences of some of their choices were discussed as were the professional changes that police officers could make to better support them. What they should do to help themselves when they became distressed was agreed. Response plans were gradually created and inputted onto call management systems so that response staff could respond to them as 'known individuals with emotional difficulties' and not 'random strangers causing irrational and irritating problems' (Jennings and Haworth, 2016).

\section{Evaluating the IRP}

Because of the limitations in time and resources, the scope and design of the evaluation was pragmatic and focussed on the extent to which the clinical, social and operational aims of the mentoring-style intervention were met:

1. increase personal accountability, social awareness and participation in recommended pathways [clinical and social aims] 
2. decrease the negative occupational impact on mental health staff involved in the care of HIUs [clinical and social aims]

3. reduce the risks posed by the HIUs to themselves and to the community i.e. decrease mental health police detentions and high intensity use of emergency public services [operational aims]

The extent to which the clinical and social aims were met was explored by way of semistructured interviews with all twelve members of the multi-disciplinary team [MDT] involved in the care of the HIUs who had interacted with the police officer working alongside the mental health team and other healthcare professionals. ${ }^{5}$ Members of the MDT were asked their views on the progress of the HIUs and on the strengths and limitations of the mentoring style intervention. Soon after these interviews which took place in February 2015 18 months after the start of the pilot, all the members of the MDT would meet in the same room for the first time in to discuss the potential and practicalities for future roll out.

The extent to which the operational aims were met was ascertained by using case notes to build a before and after profile for each HIU and comparing data on key performance indicators relating to police detentions under Section 136 of the Mental Health Act 1983 (amended 2007) and to usage of emergency mental health crisis public services (calls to mental health services, calls to police and police deployment, ambulance deployments, attendance at ED and mental health wards bed occupancy) in the twelve months before the start of the pilot implementation of the new model of care and twelve months and eighteen months later.

\section{Findings}

\section{Clinical and social benefits: improved patterns of behaviour}

All four HIUs made clinical progress and demonstrated improved patterns of behaviours, some more than others.

After several months of mentoring, it was a final threat of arrest and legal intervention that persuaded Jane to stop all disruptive behaviour towards emergency services. Her attempts to disrupt or sabotage the clinical progress of other service users and her abuse or threats towards emergency public services staff also stopped and her family re-engaged. Jane has since been discharged from mental health services.

Gena stopped using drugs and alcohol. Self-harming by cutting also decreased, but her eating disorder worsened (although clinical staff felt this was a sign of clinical progress). She continued to display 'attention-seeking' behaviours but these were low risk and primarily within NHS settings rather than in public places. She can work in a more structured way with mental health services. However, in a sporadic incident at her home address, she stabbed her boyfriend with a kitchen knife after he did not pay her enough attention. Her mentoring team supported her through court and made suitable representations. She was found guilty of Grievous Bodily Harm [GBH] and given Community Behaviour and Probation Orders. If she

\footnotetext{
${ }^{5} 1$ NHS Consultant (i.e. Attending) Psychiatrist, 1 NHS Clinical Psychologist, 7 NHS community care co-ordinators/nurses, 1 NHS mental health A\&E ward nurse, 1 University research assistant, 1 Specialist mental health police sergeant, 1 Police constable working in a mental health support role
} 
does not comply, she will receive a custodial sentence for all the offences committed. Time in prison will then be wholly proportionate and wholly necessary.

Tina's suicide attempts in public places stopped and self-harm at home were reduced. It was explained to Tina that a Community Behaviour Order would be sought if her disruptive behaviour continued. She resisted and was discharged from mental health services because of non-compliance with recommended treatment plans and boundaries. She was sent a joint letter by the NHS and Police explaining why. This led to a radical rethink and a short time later she requested a return to mental health services and was allowed to re-engage. She was allocated a different mental health care co-ordinator away from the IRP. She is now making much better progress and is mindful that the same consequences are always an option again.

Susan stopped all unsafe public crisis behaviour. She no longer made abusive calls to 999 or to mental health management staff when under the influence of alcohol. She agreed that she did not belong in hospital. Her behaviour in her GP surgery and pharmacy improved. She remains vulnerable to predatory men whom she continues to invite to her flat and who take financial advantage of her. She took responsibility for her betting and made arrangements for the local betting shop to ban her by mutual consent. However, she appears to still gamble using scratch cards and is being given further support for this. She undertook activities at her local Mental Health Recovery College, which has led to higher levels of selfesteem. However, her motivation to attend and to change some of her undesirable behaviour patterns is inconsistent and based on her mood.

\section{Clinical and social benefits: positive impact on the mental health staff involved in the care of HIUs}

Members of the MDT agreed that the IRP had provided HIUs with increased individual attention and that they felt more supported, less isolated and more engaged with their mental health treatment. They were empowered to do something positive i.e. take responsibility for their actions and take better care of themselves and NOT to do something negative i.e. not calling the police, not calling the ambulance or not going to the ED to get the 'hit' of compassion they so craved.

HIUs mentored by a multi-disciplinary team incorporating a police officer alongside mental health and other professionals had changed the therapeutic dynamics for the better. The mere presence of a police officer seemed to reinforce boundary setting. One clinician said: They may never thank you for it but inside they know it is exactly what they needed. Another

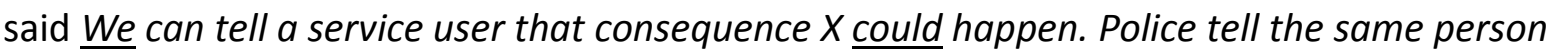
that consequence $X$ will happen.

Working alongside a police officer had enabled mental health staff to use more resilient and consistent approaches. One practitioner stated that it had become a two-parent structure. Mental health staff were less likely to tolerate unwanted and abusive behaviour and were more confident in enforcing boundaries. They experienced the IRP as promoting a focus to change, re-setting the boundaries, retuning the goals and re-booting the focus. 
Calls to mental health services significantly decreased to a handful of less anti-social, less malicious and more clinically productive calls. Mental health staff welfare and well-being at work had improved. Each boundary setting and contract made with HIUs (endorsed by the police) ensured that they could provide a better quality of care to their other patients because they did not dread coming to work anymore.

Mental health staff reported a better relationship with HIUs who showed improved attendance (on average) at mental health appointments, made fewer inappropriate telephone calls to the service and had healthier and more effective clinical relationships with care coordinators. Once 'strained and damaged' relationships had recovered to a sufficient degree to enable clinical progress, relationships could form or reform with genuine compassion.

Mental health staff expressed greater confidence about risk assessment of clinical of community risk and decision making about response planning. Sharing a risk conversation with a police officer and making a joint risk assessment was felt to be professionally safer. In particular there was had a greater awareness of potential legal powers and responsibilities and a more reliable foundation from which actions could be reviewed should any 'worst case scenario' take place.

It was acknowledged that mentoring could have negative effects on the HIUs in the short term and that attempts to empower could in fact been perceived as disempowering because previous safety nets have been removed. However, having considered both the positive and negative factors associated with 'parachuting' a police officer into the clinical pathway of a HIU, the unanimous view was that the positive benefits of integrating police and NHS far outweighed any possible negative factors and that the new multi-agency mentoring model was a worthwhile project that had the potential for future roll out.

\section{Operational benefits: positive impact on emergency public services}

The IRP was not designed to save money. However, it was found to have the potential to make substantial savings. Using figures from the Commissioning Support Unit [CSU] and on the assumption that without any intervention, the demand from the HIUs would have remained the same, the average 'savings' per HIU through costs prevented was $f 11,780$ after 18 months. See table 1. 
Table1: Average service usage per HIU 12 months before and 18 months after intervention

\begin{tabular}{|c|c|c|c|c|c|c|c|}
\hline & \multicolumn{2}{|c|}{$\begin{array}{l}\text { Average number } \\
\text { per HIU }\end{array}$} & \multirow[t]{2}{*}{$\begin{array}{l}\% \\
\text { reduction }\end{array}$} & \multirow[t]{2}{*}{$\begin{array}{l}\text { Unit } \\
\text { cost }\end{array}$} & \multicolumn{2}{|c|}{$\begin{array}{l}\text { Average cost per } \\
\text { HIU }\end{array}$} & \multirow{2}{*}{$\begin{array}{l}\text { Average } \\
\text { 'savings' } \\
\text { per HIU }\end{array}$} \\
\hline & $\begin{array}{c}12 \\
\text { months } \\
\text { pre }\end{array}$ & $\begin{array}{c}18 \\
\text { months } \\
\text { post }\end{array}$ & & & $\begin{array}{c}12 \\
\text { months } \\
\text { pre }\end{array}$ & $\begin{array}{c}18 \\
\text { months } \\
\text { post }\end{array}$ & \\
\hline $\begin{array}{l}\text { S136 police } \\
\text { detentions }\end{array}$ & 8.75 & 0 & 100 & $£ 645$ & $f 5,644$ & 0 & $£ 5,644$ \\
\hline ED visits & 12 & 4 & 67 & $f 80$ & $f 960$ & $£ 320$ & $£ 640$ \\
\hline $\begin{array}{l}\text { Police } \\
\text { deployment }\end{array}$ & 11 & 4 & 64 & f45 & $£ 495$ & $f 180$ & f315 \\
\hline $\begin{array}{l}\text { Ambulance } \\
\text { deployments }\end{array}$ & 7.5 & 3 & 60 & $f 208$ & $f 1,560$ & $f 624$ & £936 \\
\hline $\begin{array}{l}\text { MH ward bed } \\
\text { occupancy }\end{array}$ & 15 & 0 & 100 & $£ 283$ & $f 4,245$ & $£ 0$ & $£ 4,245$ \\
\hline & & & & Total & $£ 12,904$ & $£ 1,124$ & $£ 11,780$ \\
\hline
\end{tabular}

The number of police mental health crisis detentions under section 136 of the Mental Health Act 1983 (amended 2007) ( $n=35)$ was reduced by 66\% ( $n=12)$ after 12 months and by $100 \%$ after 18 months. The use of other emergency public services had been greatly reduced after 12 months and stopped completely for two HIUs and were drastically reduced for the other two. The use of emergency public services including mental health crisis detentions had decreased by $78 \%$ while the 'savings' through costs prevented had decreased by $91 \%$.

\section{Discussion}

\section{Implications for practice}

Members of the MDT underlined that patients with EUPD and/or BPD, such as the four HIUs, often experience isolation and acute levels of low self-esteem, seeking attention at any opportunity, more particularly in less sociably acceptable ways (Singleton et al, 1998; NICE, 2009) and that the supportive and compassionate mentoring style of the IRP had led to operational, clinical and social benefits in a context in which mental health services had been powerless to reduce or stop high intensity use of emergency public service.

All the members of the MDT agreed that the pilot mentoring style intervention should be rolled out for the mutual benefit of both service users and of the multi-disciplinary team who had benefitted from shared learning. In fact, an unintended consequence of shared learning was that the police officer became more like mental health professionals and vice versa. In particular, the police officer was able to guide mental health staff in how they could be more effective while mental health staff showed the police officer how to be more thoughtful and more caring.

The journey from designing to implementing and evaluation the new mentoring model of care led to the following implications for practice: 
1. THE USE OF POLICE PRESENCE: This can be a powerful positive factor, but could also cause embarrassment and emotional discomfort if handled incorrectly and could increase the risk of formal prosecution outcomes.

2. RISK OF A NEGATIVE REACTION: Any new clinical approach can generate strong initial resistance and result in complaints, obstruction or sabotaging clinical treatment.

3. BOUNDARY SETTING: This can provide reassurance but can also threaten identity or life choices, causing stress and behavioural resistance.

4. INITIAL CRISIS DEMAND 'SPIKE': This may go up at the beginning of the IRP programme or the pattern of demand may change in response to boundary setting. Instead of calling the police, there may be an increased demand for ambulance or going to $A \& E$ directly.

5. RISKS ARE UNPREDICTABLE: Risks to the community and to HIUs were noticeably reduced over time, but fluctuated and were often unpredictable in the short term. The mentoring model must have a risk assessment tool built into practices.

6. ALWAYS BE PREPARED FOR MALICIOUS ACCUSATIONS against family members or against IRP team members - which may not happen, but it is best to be prepared

7. DISCHARGE IS NOT A FAILURE: If the mentoring fails to bring about any progress, then the option of discharge from mental health or social care services can then be considered as a fair and proportionate measure. This both reinforces behavioural expectations and protects staff from unwanted anti-social behaviour.

\section{Implications for research}

Quality improvement initiatives implemented in real-world settings such as the present small scale case study are shaped by the specific contexts and circumstances in which they are implemented and are very difficult to evaluate using methodologies such as randomised controlled trials and control groups. Serious methodological limitations are found in most evaluations of CIT schemes in the USA (Helfgott et al, 2016), the small number of evaluations of STs England (Wilson-Palmer and Poole, 2015; Dyer et al, 2015; Heslin et al, 2016; Keown et al, 2016; Irvine et al, 2016; Reveruzzi and Pilling, 2016) and the interventions in the USA aimed only at HIUs (Council of State Governments Justice Centre, 2012 , 2015). Due to both shortcomings in data collection, lack of time and resources, and national and local policy based priorities, evaluations of these interventions have tended to be descriptive and focus primarily on stakeholder satisfaction, decreased service usage and to a limited extent cost-effectiveness. Focussing on HIUs, a small number of people who use emergency public services in a disproportionate way means even smaller samples than studies of ST. Thus, future studies could usefully undertake both non-participant observation of what happens during the mentoring sessions and interviews with HIUs, and members of the MDT to gain insights into their experience of the mentoring process.

\section{Implications for policy}

Even if primarily descriptive and, more often than not, without control groups, pragmatic evaluations of quality improvement interventions in real world settings, such as the present small-scale case study, still provide valuable insights in relation to potential benefits of new models of care aimed at reducing both the number mental health police detentions and usage of emergency public services especially the demand from frequent users (Watson, 2010). 
Despite the small sample, more effective clinical relationships with care coordinators and great improvement in the before and after profile and in key performance indicators pre and post intervention especially reduction is service usage (78\%) and anticipated costs (91\%) (See table 1) provided sufficient evidence of the potential clinical, social and operational benefits and cost effectiveness of the mentoring style intervention that the Isle of Wight Clinical Commissioning Group and Hampshire Isle of Wight Constabulary agreed to roll out of the pilot and to employ a police officer with the reduction in anticipated costs in effect subsidising the salary of the police officer.

Although small scale, the pilot study has implications for policy as it might help communities make resource decisions about police/mental health partnerships (Helfgott et al, 2016) and encourage policy makers to invest more resources into new models of care or quality improvement interventions that can potentially save costs and guarantee a good return on investment.

\section{Conclusion}

This paper has described the design, implementation and evaluation of a small UK case study of a mentoring-style pilot intervention, a new model of care integrating a police officer alongside mental health professionals within the mental health treatment pathway of HIUs of emergency services.

\section{Limitations}

Limited time and resources and the need for a solution that could be implemented as soon as possible meant a pragmatic design, implementation and evaluation and a very small sample. The case examples and figures for reduced service usage are therefore used for demonstrative purpose to underline their implications for practice, policy and research. No prior research into the conceptual frameworks and effectiveness of other well-known mentoring models was undertaken. Nonetheless, the IRP mentoring style approach is broadly aligned with some well-known mentoring models, whether general (e.g. Egan, 2002, 2006) or for those suffering from addiction (i.e. Prochaska et al, 1999). Service users were not involved in the design and development (Avis, 1997; Bevan and Fairman, 2014). The views of the HIUs were not sought as part of the evaluation (Avis, 1997; Bevan and Fairman, 2014). Data about use of emergency and mental health services post IRP was not available to be compared with that of the other four HIUs who could have functioned as a control group. Finally, the evaluation would have been enhanced with a wider range of data sources had the members of the MDT completed validated questionnaires (e.g. May and Finch, 2009) about the extent of routine embedding in day to day work

\section{Value-added}

Despite its methodological limitations, the IRP is unique insofar as not only was its design based on clinical core principles derived from guidelines for BPD (NICE, 2009) and on policy endorsed recommendations (Docking, 2008; Bradley, 2009; Adebawole 2013; HM Government, 2014), all of which underline the importance of adopting a psycho-social approach (Durcan, 2014), but it is also the first intervention aimed at HIUs with complex mental health needs to directly integrate a police officer in the care pathway of HIUs. 
The only other intervention in England aimed at HIUs of emergency public services with complex mental health involved police officers and mental health professionals in promoting community based supportive social networks and access to meaningful activity rather than police officers being directly integrated in the care pathway of HIUs (MHN NHS Confederation and ACPO, 2015).

Apart from the introduction of a preventative and follow-up element for HIUs within CITs pairing police officers and mental health practitioners to attend mental health-related calls in Akron, $\mathrm{OH}$ (Munetz et al, 2006) and Seattle, WA (Helfgott et al 2016), only two interventions (Houston and Los Angeles) have focussed solely on identifying and supporting HIUs with complex mental health needs (Council of State Governments Justice Center, 2012, 2015). In Houston, police officers helped connect HIUs to mental health and psychosocial services to provide them with additional support and education (Council of State Governments Justice Center, 2015). In Los Angeles, although both mental health practitioners and police officers were involved in separate profiling and interviewing of HIUs, they then were directed to the relevant health and social care services (Council of State Governments Justice Centre, 2012). In neither of these interventions were police officers directly integrated into the care pathway of HIUs.

\section{Serenity Integrated Mentoring [SIM]}

When it was rolled the mentoring-style intervention changed its name to SIM [Serenity Integrated Mentoring]. Hampshire Constabulary now employ a full-time SIM officer ${ }^{6}$ funded by the Isle of Wight Clinical Commissioning Group to support the emotional and behavioural needs of HIUs and/or of emergency public services users who are starting to show the first signs of escalating behaviour while they work through their difficulties and are expected to make healthier life choices and address any inappropriate behavioural responses that impact negatively on others. The SIM model has already been adopted by one Wessex area and by another area outside Wessex. Two other sites outside Wessex are about to start discussing the potential planning phase and more have expressed an interest. ${ }^{7}$

\footnotetext{
${ }^{6}$ The cost of this officer is $£ 36,000$ a year and $50 \%$ of the salary is paid by the Isle of Wight NHS Foundation Trust until April 2017 . We expect that this work will prevent over $£ 100,000$ of clinical treatment each year.

${ }^{7}$ In October 2016, SIM won the prestigious HRH Prince of Wales Award for Integrated Care at the Nursing Times Awards 2016. In November 2016, SIM was chosen as one of just eight healthcare solutions across the NHS to be supported by the NHS Innovation Accelerator Programme. Operation Serenity, IRP and SIM were deemed Outstanding (CQC Inspection 2014) and Highly Commended (Positive Practice in Mental Health Awards 2013).

For more information on developing a SIM high intensity team, please contact: simenquiries@gmail.com

For more information on the NHS Innovation Accelerator Fellowship: https://www.england.nhs.uk/ourwork/innovation/nia/casestudies/paul-jennings/
} 


\section{References}

Adebowale L. (2013) Independent Commission on Mental Health and Policing Report. Turning Point. Available at http://www.turningpoint.co.uk/media/621030/independent commission on mental health and policing main report.pdf [Accessed 22 April 2016]

Andrews G, Baldry E. (2013) Mental health frequent presenters: key concerns, case management, approaches, and policy and programme considerations for emergency services. In: Chappell D, editor. Policing and the mentally ill. London: CRC 2013. p. 197218.

Avis M. (1997) Incorporating patients' voices in the audit process. Qual Health Care, 6, 2, 8691.

Bevan $\mathrm{H}$ and Fairman S. (2014) The new era of thinking and practice in change and transformation: a call to action for leaders of health and care. NHS Improving Quality. Available from: http://www.nhsiq.nhs.uk/resource-search/publications/whitepaper.aspx [Accessed March 2015]

Bradley K. (2009) The Bradley Report: Lord Bradley's review of people with mental health problems or learning disabilities in the criminal justice system. Available at http://tinyurl.com/p9lxc5y [Accessed 6 May 2016]

Care Quality Commission. (2014) Monitoring the Mental Health Act in 2012/2013. Available: http://www.cqc.org.uk/sites/default/files/documents/cqc mentalhealth 20121307 update.pdf [Accessed 11 February 2014]

Compton MT, Bahora M, Watson A and Oliva J. (2008) A comprehensive review of extant research on crisis intervention team (CIT) programs. The Journal of the American Academy of Psychiatry and the Law, 36, 47-55

Council of State Governments Justice Centre. (2012) Innovative Law Enforcement Strategies for Interacting with People that Frequently Require Emergency and Crisis Services. July 31. Available at https://csgjusticecenter.org/law-enforcement/webinars/webinararchive-innovative-law-enforcement-strategies-for-interacting-with-people-thatfrequently-require-emergency-and-crisis-services/[Accessed 10 January 2017]

Council of State Governments Justice Centre. (2015) Reducing Emergency Care by Connecting Frequent Users to Community-Based Services. August 1. Available at https://csgjusticecenter.org/mental-health/publications/reducing-emergency-care-byconnecting-frequent-users-to-community-based-services/[Accessed 10 January 2017]

Department of Health. (2001) Changing the Outlook. A Strategy for Developing and Modernising Mental Health Services in Prison. London: Department of Health

Department of Health. (2015) 2010 to 2015 government policy: mental health service reform. Available at https://www.gov.uk/government/publications/2010-to-2015- 
government-policy-mental-health-service-reform/2010-to-2015-government-policymental-health-service-reform

Docking M, Grace K and Bucke T. (2008) Police custody as a place of safety. Examining the use of Section 136 of the Mental Health Act 1983. IPCC Research and Statistics Series: Paper 11. Available at https://www.ipcc.gov.uk/sites/default/files/Documents/section 136.pdf or tinyurl.com/no8bvys [Accessed 4 May 2016]

Durcan G. (2014) Keys to Diversion: Best Practice for Offenders with Multiple Needs. London: Centre for Mental Health

Dyer W, Steer M, Biddle P. (2015) Mental health street triage. Policing, 9, 377-387. DOI: https://doi.org/10.1093/police/pav018 [Accessed 10 January 2017]

Egan G. (2002) The Skilled Helper: problem management approach to helping [ $7^{\text {th }}$ edition] Pacific Grove, CA: Brooks Cole

Egan G. (2006) Essentials of Skilled Helping: managing problems, developing opportunities Pacific Grove, CA: Brooks Cole

Health and Social Care Information Centre. (2013) Inpatients formally detained in hospitals under the Mental Health Act 1983, and patients subject to supervised community treatment Annual report, England. Available: http://www.hscic.gov.uk/catalogue/PUB12503/inp-det-m-h-a-1983-sup-com-eng-1213-rep.pdf [Accessed 4 May 2016]

Helfgott JB, Hickman MJ, Labossiere AP. (2016) A descriptive evaluation of the Seattle Police Department's crisis response team officer/mental health professional partnership pilot program. International Journal of Law and Psychiatry, 44, 109-122

Her Majesty's Inspectorate of Constabulary, Her Majesty's Inspectorate of Prisons, the Care Quality Commission and Healthcare Inspectorate Wales. (2013) A criminal use of police cells? The use of police custody as a place of safety for people with mental health needs. Available at http://www.justiceinspectorates.gov.uk/hmic/media/a-criminal-use-ofpolice-cells-20130620.pdf [Accessed 5 May 2016]

Heslin M, Callaghan L, Packwood M, Badu V and Byford S. (2016) Decision analytic model exploring the cost and cost-offset implications of street triage. BMJ Open 6: e009670. DOI:10.1136/bmjopen-2015-009670

Her Majesty's Government. (2014) Mental Health Crisis Care Concordat - Improving outcomes for people experiencing mental health crisis. Available at www.crisiscareconcordat.org.uk [Accessed 5 May 2016]

Irvine AL, Allen L, Webber MP. (2016) Evaluation of the Scarborough, Whitby and Ryedale Street Triage Service. York, UK: Department for Social Policy and Social Work, University 
of York. Available at http://eprints.whiterose.ac.uk/94059/1/STRfinalreport.pdf

[Accessed 24 January 2017]

Jennings P, Haworth V. (2015) Serenity Integrated Mentoring [SIM] Specialist Support for High Intensity Mental Health Crisis. Developing a National Research Network.

Southampton: Hampshire Isle of Wight Constabulary, Isle of Wight NHS Trust.

Keown P, French J, Gibson G, Newton E, Cull S, Brown P, Parry J, Lyons D and McKinnon I. (2016) 'Too much detention? Street Triage and detentions under Section 136 Mental Health Act in the North-East of England: a descriptive study of the effects of a Street Triage intervention.' BMJ Open. 6, 11, e011837. DOI: 10.1136/bmjopen-2016-011837

Legislation.gov.uk (2016) Mental Health Act 1983 and 2007. National Archives. Available at http://www.legislation.gov.uk/ukpga/1983/20/section/136 [Accessed 4 May 2016]

May C and Finch T. (2009) Implementation, embedding, and integration: an outline of Normalization Process Theory. Sociology 43, 3, 535-554

McNicoll A. (2012) Why are Mental Health Act detentions by police on the rise? Available at: http://www.communitycare.co.uk/blogs/mental-health/2012/08/why-are-moremental-health-pat/ [Accessed 5 May 2016]

Mental Health Network NHS Confederation and Association of Chief Police Officers. (2015) Mental health and policing. Improving crisis care. Briefing. Available at http://www.nhsconfed.org/ /media/173E13442E2C470997D3F87370211F7E.ashx [Accessed 4 May 2016]

Munetz MR, Morrison A, Krake J, et al (2006) Statewide implementation of the Crisis Intervention Team program: the Ohio model. Psychiatr Serv 57:1569-71

National Institute of Care and Excellence [NICE]. (2009) Borderline personality disorder: recognition and management Guidelines [CG78]. Available at https://www.nice.org.uk/guidance/cg78 [Accessed 5 May 2016]

NHS England AUEC Review Team and ECIST [Emergency Care Intensive Support Team] [Keogh Report]. (2025) Transforming urgent and emergency care services in England. Safer, faster, better: good practice in delivering urgent and emergency care. A guide for local health and social care communities. Available at http://www.nhs.uk/NHSEngland/keogh-review/Documents/safer-faster-better-v28.pdf [Accessed 4 May 2016]

O'Hara M. Fixing the UK's mental health crisis will need both police and health. (2016) The Guardian, 3 February. Available at http://www.theguardian.com/public-leadersnetwork/2016/feb/03/uk-mental-health-crisis-police [Accessed 5 May 2017]

Parliament.UK. (2015) Policing and mental health - Home Affairs Police and health service collaboration. Street triage. Available at 
http://www.publications.parliament.uk/pa/cm201415/cmselect/cmhaff/202/20206.ht $\underline{m}$ [Accessed 10 May 2016]

Prochaska J, DiClimente C, and Norcross J. (1999) In search of how people change. American Psychologist, 47, 9, 1102-1114

Reuland M, Draper L, Norton B. (2010) Improving responses to people with mental illnesses: Tailoring law enforcement initiatives to individual jurisdictions. Available at: http://consensusproject.org/jc publications/tailoring le responses/Tailoring LE Initiat ives.pdf [Accessed 21 December 2016]

Reveruzzi B and Pilling S. (2016) Street Triage. Report on the evaluation of nine pilot schemes in England. University College London. Available at https://www.ucl.ac.uk/pals/research/cehp/research-groups/core/pdfs/street-triage [Accessed 7 December 2016]

Royal College of Psychiatrists. (2011) Standards on the use of Section 136 of the Mental Health Act 1983 (England and Wales). Available at http://www.rcpsych.ac.uk/files/pdfversion/CR159x.pdf [Accessed 25 April 2016]

Salovey P, Mayer J and Caruso D. (2004) Emotional Intelligence: Theory, Findings, and Implications. Psychological Inquiry, 197-215Singleton N, Meltzer H, Gatward R, Coid J and Deasy D. (1998) Psychiatric morbidity among prisoners: a summary report. London: Office for National Statistics and Department of Health / The Stationary Office

Watson AC. (2010) Research in the Real World: Studying Chicago Police Department's Crisis Intervention Team Program. Research on Social Work Practice 20, 5: 536-43.

Wilson-Palmer K and Poole R. (2015) Street triage for mental health crises. British Journal of Nursing, 24, 20, 1026-1028

\section{Biographies}

Paul Jennings (BSc (Hons), PGCertTheol, CMI Level 7 Strategic Mngt, CMI Level 7 Coaching Mentoring is a specialist Mental Health Sergeant at Hampshire Constabulary and Visiting Professor at John Jay College of Criminal Justice in New York. He is currently project lead for a Department of Health funded specialist mental health ambulance and one of eight fellows with the NHS England Innovation Accelerator Programme.

Dr Catherine B Matheson-Monnet (MA, CertCouns, MSc, PhD, FHEA, Mentoring in Healthcare Organisations 30 credit level 7) is a Senior Research Fellow in the Centre for Implementation Science at the University of Southampton. She is currently involved in a research and evaluation of healthcare related quality improvement projects spanning respiratory, primary care, malnutrition and the elderly, dementia, mental health and integrated models of care. 
